Gut, 1973, 14, 365-368

\title{
Liver disease and cell-mediated immunity in hepatitis-associated antigen (HAA) carriers
}

\author{
T. D. BOLIN, A. E. DAVIS, AND A. G. LIDDELOW \\ From the School of Medicine, University of New South Wales, Prince Henry Hospital, and the Department \\ of Pathology, Prince of Wales Hospital, Sydney, Australia
}

SUMMARY As the incidence of liver disease in hepatitis-associated antigen (HAA) carriers has not been defined and it has been postulated that continuing liver disease is associated with incompetence of the cell-mediated immune system, a prospective study was undertaken to examine both these points.

An increased incidence of HAA carriers was found in a prison population (1.3\%). Eighteen of these subjects gave informed consent to further study with liver function tests, liver biopsy, and testing of cell-mediated immunity with dinitrochlorobenzene (DNCB) skin sensitization.

Liver function tests were normal in 10 subjects, mildly abnormal in six (SGPT < 100 IU/litre), and abnormal in two. Serum proteins were normal in all.

Liver biopsy showed that five subjects had chronic aggressive hepatitis, three of whom had normal liver function tests. Eight subjects had persistent hepatitis, three with normal liver function tests. The remainder had acute hepatitis (1), evidence of residual hepatitis (1), or non-specific changes (2). Only one subject had normal histology. Drug addicts, who comprised $56 \%$ of the group, had more severe liver disease then those who were not addicts.

The hypothesis that persisting liver disease is associated with impaired cell-mediated immunity was not confirmed in that nine of the 12 subjects with persistent or chronic aggressive hepatitis had a positive response to dinitrochlorobenzene skin sensitization, thus implying normal cell-mediated immunity. The findings of this study suggest that in the presence of continuing antigenaemia liver biopsy is mandatory in order to disclose treatable liver disease.

There is an increased incidence of chronic liver disease in patients recovering from hepatitis associated with persisting antigenaemia (Prince, Hargrove, and Jeffries, 1969). However, reports on the incidence of liver disease in asymptomatic HAA carriers are conflicting. Reports from Denmark (Banke, Dybkjaer, Nordenfelt, and Reinicke, 1971; Reinicke, Dybkjaer, Poulsen, Banke, Lylloff, and Nordenfelt, 1972) indicate a very low incidence of histological abnormalities in HAA carriers in contrast to reports from America which indicate that a substantial proportion of subjects have liver disease (Prince, Hargrove, and Jeffries, 1969; Singleton, Fitch, Merrill, Kohler, and Rettberg, 1971). It has been postulated that persistence of liver disease after hepatitis results from an incompetent cell-mediated

Received for publication 8 February 1973 immune system (Dudley, Fox, and Sherlock, 1972). For these reasons a prospective study was undertaken to determine the incidence and severity of liver disease in asymptomatic HAA carriers and to test their cell-mediated immune system.

\section{Patients and Methods}

One thousand five hundred and fifty male subjects in the care of the Department of Corrective Services in Sydney were screened by the NSW Red Cross Blood Transfusion Service for the presence of HAA by immunoelectrophoresis (Watson, Watts, and Nelson, 1972). Subjects having blood found to contain HAA were further evaluated by means of a medical history, physical examination, and biochemical study of liver function using tests for serum bilirubin, alkaline phosphatase, serum glutamic 
pyruvic transaminase (SGPT), serum proteins, and prothrombin time. It was also established whether they were drug addicts or not.

Liver biopsy was performed, using the Menghini technique, after obtaining the patient's informed consent. Tissue sections were stained for light microscopy with haematoxylin and eosin, picro-Mallory trichrome, silver reticulin, and Perls' iron stain. Some sections were also examined by electron microscopy for the presence of HAA in the liver. Cell-mediated immunity was tested with dinitrochlorobenzene skin sensitization.

\section{Results}

INCIDENCE OF HEPATITIS-ASSOCIATED

ANTIGEN CARRIERS

Twenty of the 1550 subjects studied were HAA positive $(1.3 \%)$ while one further subject was HAA negative but HA-antibody positive. Eighteen of these subjects consented to further investigation.

\section{LIVER FUNCTION}

On the basis of biochemical tests of liver function subjects could be divided into three groups: those having normal tests of liver function (10); those having a minimal abnormality manifest by elevation of the transaminase levels to less than 100 iu per litre (normal range 0-18 iu per litre), with a bilirubin level of less than $1.0 \mathrm{mg}$ per $100 \mathrm{ml}$ of blood (6); and those having a greater abnormality of liver function manifest by elevation of the transaminase above 100 iu per litre, together with a raised bilirubin level above $1.0 \mathrm{mg}$ per $100 \mathrm{ml}$ blood (2), one of these being compatible with overt acute hepatitis (table I).

\begin{tabular}{|c|c|c|c|}
\hline \multirow[t]{2}{*}{ Liver Histology } & \multicolumn{3}{|c|}{ Liuer Function Tests } \\
\hline & Normal & $\begin{array}{l}\text { Minimal } \\
\text { Abnormality } \\
(S G P T< \\
\text { lo0iu) }\end{array}$ & $\begin{array}{c}\text { Abormal } \\
(S G P T> \\
\text { lo0iu) }\end{array}$ \\
\hline
\end{tabular}

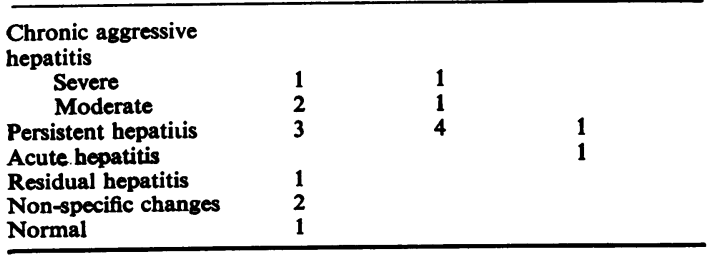

Table I Relationship of liver function tests to liver histology in HAA carriers

LIVER HISTOLOGY

A liver biopsy was performed on 18 of 21 subjects.
Liver histology and its relationship to liver function tests is shown in table I. Thirteen subjects showed evidence of chronic hepatitis and were further classified as persistent hepatitis, moderate aggressive, and severe aggressive hepatitis, according to the criteria of the European Association for the Study of the Liver (De Groote, 1968). Five subjects had chronic aggressive hepatitis, severe in two and moderate in three. The figure shows the histological changes in one of the cases of severe aggressive hepatitis with early cirrhosis. Eight subjects had evidence of persistent hepatitis, one subject had acute hepatitis, two subjects had non-diagnostic changes, and one had residual evidence of hepatitis which was now inactive. Only one subject had normal histology.

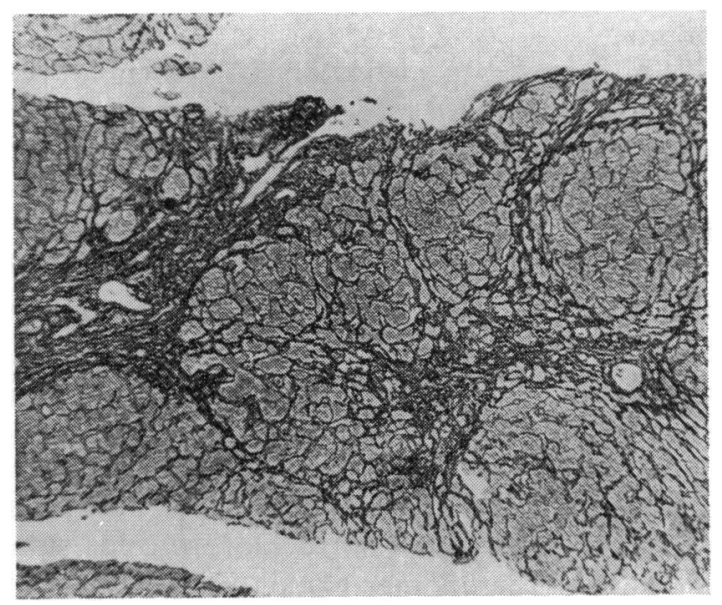

Fig. Severe aggressive hepatitis with early cirrhosis (reticulin: $\times 75)$ and normal liver function tests.

The five subjects with chronic aggressive hepatitis were of great interest in that the changes were severe in two and associated with early cirrhosis while the liver function tests were normal in three of the subjects (including one subject with cirrhosis); the other two had only minimal elevation of transaminases to 34 and 93 iu per litre. Three of the eight subjects with persistent hepatitis had normal liver function tests; four had a minimal abnormality with transaminase levels ranging from 34 to 75 iu per litre and one had an initial SGPT of 435 iu per litre with a normal bilirubin. The remaining patients with evidence of residual hepatitis or non-specific changes had normal liver function tests. One subject developed overt hepatitis with abnormal liver function tests.

Electron microscopy for HAA in liver tissue of four subjects with persistent hepatitis failed to 
demonstrate the antigen. Intranuclear HAA was, however, detected in one subject with severe chronic aggressive hepatitis.

\section{THE RELATIONSHIP OF LIVER DISEASE TO} ADDICTION

Ten subjects $(56 \%)$ were addicts and all had abnormal liver histology (table II), four having chronic aggressive hepatitis. Eight subjects $(44 \%)$ were not addicts and only one had chronic aggressive hepatitis; he had a history of excessive alcohol intake. Four subjects had evidence of persistent hepatitis, two had non-specific changes, and one was normal (table II).

\begin{tabular}{lll}
\hline Hepatitis & Addict & Non-addict \\
\hline Chronic aggressive & 4 & 1 \\
Persistent & 4 & 4 \\
Acute & 1 & 0 \\
Residual & 1 & 0 \\
Non-specific changes & 0 & 2 \\
Normal & 0 & 1 \\
\hline
\end{tabular}

Table II Liver histology in addicts and non-addicts

CELL-MEDIATED IMMUNITY

The relationship of liver histology to cell-mediated imnunity in 16 subjects, as judged by dinitrochlorobenzine skin sensitization, is indicated in table III. From this it can be seen that nine of the 12 subjects with chronic aggressive or persistent he: atitis had normal cell-mediated immunity as judged by this test, thus failing to confirm the hypothesis that persistent or chronic aggressive hepatitis is dependent on an incompetent cell-mediated immune system.

\begin{tabular}{|c|c|c|c|c|}
\hline \multirow[t]{3}{*}{ Histology } & \multicolumn{4}{|c|}{ Dinitrochlorobenzene Skin Sensitization } \\
\hline & \multicolumn{3}{|c|}{ Positive } & \multirow[t]{2}{*}{ Negative } \\
\hline & Strong & Medium & Weak & \\
\hline $\begin{array}{l}\text { Chronic aggressive } \\
\text { hepatitis } \\
\text { Persistent hepatitis } \\
\text { Residual hepatitis } \\
\text { Non-specific changes } \\
\text { Normal }\end{array}$ & 1 & $\begin{array}{l}3 \\
2 \\
1 \\
1\end{array}$ & $\begin{array}{l}3 \\
1 \\
1\end{array}$ & $\begin{array}{l}1 \\
2\end{array}$ \\
\hline
\end{tabular}

Table III Relationship of cell-mediated immunity to liver histology

\section{CLINICAL FINDINGS}

Only four subjects gave a history of previous hepatitis, three of these having chronic aggressive hepatitis. Four subjects had a palpable liver, two of these having chronic aggressive hepatitis, one continuing hepatitis, and the other acute hepatitis. In the last patient liver size returned to normal.

\section{Discussion}

A high incidence of HAA-positive carriers was confirmed in a prison population $(1.3 \%$ ) (Watson et al, 1972), this incidence being similar to reports from other centres (Kliman, 1971; Muniz, Malyska, and Levin, 1971; Chalmers and Alter, 1971; Kliman, Reid, Lilly, and Morrison, 1971; Krotoski, 1972).

The important additional information disclosed by this study is that severe progressive liver disease can occur in the presence of normal liver function as judged by the standard liver function tests. The experience of Banke et al (1971), who biopsied 17 of 18 HAA-positive donors in Copenhagen and found no histological abnormalities, is similar to the findings of Reinicke'et al (1972), but is in con trast to this study and those of Prince et al (1969) and Singleton Fitch, Merrill, Kohler, and Rettberg, (1971). Prince, Hargrove, and Jeffries (1969) studied 14 of 23 HAA carriers and found seven of these to have either chronic aggressive hepatitis or cirrhosis associated with an abnormality of transaminase levels. A further five subjects had normal or minimally abnormal liver histology while two had acute hepatitis. Singleton et al (1971) biopsied 10 of 25 HAA-positive donors, and of four who were clinically normal, one had cirrhosis, one had persistent hepatitis, and two had non-specific change. A further four subjects with abnormal liver function had either persistent or chronic active hepatitis. The contrast in the incidence of liver disease between these and other studies is not explained, but the present study has shown a greater incidence of severe liver disease in addicts than in those not addicted, and it is conceivable that drug addiction is an important factor influencing the presence of significant liver disease. Cherubin, Rosenthal, Stenger, Prince, Baden, Strauss, and McGinn (1972) reported a high incidence of chronic aggressive and persistent hepatitis in necropsies on addicts dying from acute intravenous narcotism or trauma. Also, three former addicts with persistent antigenaemia and normal liver function tests were found to have chronic aggressive hepatitis. However, the patients studied by Singleton et al (1971) were predominantly not addicts and yet a relatively high incidence of chronic liver disease was found.

In contrast to the classical chronic active hepatitis which particularly affects young women, the serum protein and globulin levels were normal in all subjects. Clinical findings, such as enlargement of the liver, were no guide to the presence of significant 
liver disease, and there were none of the clinical stigmata associated with classical chronic active hepatitis.

Dudley et al (1972) have postulated that continuing liver disease is associated with incompetence of the cell-mediated immune system, while complete recovery of hepatitis occurs in the presence of a normal cell-mediated immune system. This study has shown no correlation between cell-mediated immunity, as judged by dinitrochlorobenzene sensitization, and the chronicity of the liver disease. In fact, nine of the 12 subjects with either persistent or chronic aggressive hepatitis had a normal cellmediated immune system. It is realized that no single test, such as dinitrochlorobenzene skin sensitization, is a reliable guide to cell-mediated immunity, but there is as yet no agreement on a suitable test. It was recognized that sampling errors occur on liver biopsy (Soloway, Baggenstoss, Schoenfield, and Summerskill, 1971), but as the changes of hepatitis are diffuse this error is trivial in contrast to the considerable sampling error found in the presence of cirrhosis. It is therefore possible that the histological abnormalities detected in this study could have been of greater magnitude if due allowance is made for sampling error.

The findings in this study suggest that in the presence of persisting antigenaemia liver biopsy is mandatory in order to disclose treatable liver disease such as chronic aggressive hepatitis. In the presence of persistent hepatitis it is recommended that the liver biopsy be repeated at an interval of two to three months to determine whether the hepatitis has resolved or is progressing towards chronic aggressive hepatitis.
We are indebted to Dr G. Archer, Director New South Wales Red Cross Blood Transfusion Service, and Pam Woolley, Margaret Nelson, and Diana van Driel for their assistance.

References

Banke, O., Dybkjaer, E., Nordenfelt, E., and Reinicke, V. (1971). Australia antigen and antibody in 10000 Danish blood donors. Lancet, 1, 860-861

Chalmers, T. C., and Alter, H. J. (1971). Management of the asymptomatic carrier of the hepatitis-associated (Australia) antigen. New Engl. J. Med., 285, 613-617.

Cherubin, C. E., Rosenthal, W. S., Stenger, R. E., Prince, A. M., Baden, M., Strauss, R., and McGinn, T. G. (1972). Chronic liver disease in asymptomatic narcotic addicts. Ann. intern. Med., 76, 391-395.

De Groote, J., Desmet, V. J., Gedigk, P., Korb, G., Popper, H., Poulsen, H., Scheuer, P. J., Schmid, M., Thaler, H., Uehlinger, E., and Wepler, W. (1968). A classification of chronic hepatitis. Lancet, 2, 626-628.

Dudley, F. J., Fox, R. A., and Sherlock, S. (1972). Cellular immunity and hepatitis-associated, Australia antigen liver disease. Lancet, 1, 723-726.

Kliman, A. (1971). Australia antigen in volunteer and paid blood donors. New Engl. J. Med., 284, 109.

Kliman, A., Reid, N. R., Lilly, C., and Morrison, J. (1971). Hepatitisassociated antigen (Australia antigen) in Massachusetts blood donors. New Engl. J. Med., 285, 783.

Krotoski, W. A. (1972). Hepatitis in prison blood donors. New Engl. J. Med., 286, 159.

Muniz, F. J., Malyska, H., and Levin, W. C. 1971). Au antigen in blood from prisoners. New Engl. J. Med., 284, 501-502.

Prince, A. M., Hargrove, R. L., and Jeffries, G. H. (1969). The role of serum hepatitis virus in chronic liver disease. Trans. Ass. Amer. Phycns, 82, 265-277.

Reinicke, V., Dybkjaer, E., Poulsen, H., Banke, O., Lylloff, K., and Nordenfelt, E. (1972). A study of Australia-antigen-positive blood donors-and their recipients, with special reference to liver histology. New Engl. J. Med., 286, 867-870.

Singleton, J. W., Fitch, R. A., Merrill, D. A., Kohler, P. F., and Rettberg, W. A. H. (1971). Liver disease in Australia-antigenpositive blood-donors. Lancet, 2, 785-787.

Soloway, R. D., Baggenstoss, A. H., Schoenfield, L. J., and Summerskill, W. H. J. (1971). Observer error and sampling variability tested in evaluation of hepatitis and cirrhosis by liver biopsy. Amer. J. dig. Dis., 16, 1082-1086.

Watson, P. T., Watts, J. R., and Nelson, M. (1972). The incidence of Australia antigen and antibody in male prisoners of two Sydney penitentiaries. (In press). 